\title{
A FORMAÇÃO DO DIRETOR DE ESCOLA: LIMITES E POSSIBILIDADES NA CONJUNTURA DA POLítica EDUCACIONAL ATUAL
}

\author{
THE TRAINING OF THE SCHOOL DIRECTOR: LIMITS AND POSSIBILITIES IN THE CONJUNCTURE \\ OF CURRENT EDUCATIONAL POLICY \\ LA FORMACIÓN DEL DIRECTOR DE ESCUELA: LÍMITES Y POSIBILIDADES EN LA COYUNTURA \\ DE LA POLÍTICA EDUCACIONAL ACTUAL
}

\begin{abstract}
Eduardo Santos Araújo
Universidade Federal de Juiz de Fora - UFJF

Secretaria de Estado de Educação de Minas Gerais

E-mail: eduardoaraujo.araujoeduardo@gmail.com
\end{abstract}

\begin{abstract}
RESUMO
O trabalho ora apresentado discute a formação de diretores de escolas de educação básica como fator preponderante para que se alcance melhoria na qualidade educacional pública. Com recorte prioritário na rede de estado de educação de Minas Gerais, as políticas públicas (relativas ao tema) disponíveis são apresentadas e brevemente analisadas. A partir de Lück (2000 e 2009), Paro (2010), Teixeira e Malini (2012), entre outros, é construída a base teórica que visa responder à pergunta: Por que formar diretores? A partir dos hiatos formativos constatados, a importância do trabalho se constrói em torno do anúncio da carência de políticas públicas mais sistematizadas na rede estadual de educação em tela. Depreende-se que este tipo de pesquisa pela academia pode ser preponderante no processo de indicação do tema para inserção na agenda das políticas público-educacionais.
\end{abstract}

PALAVRAS-CHAVE: Formação de diretores. Políticas públicas educacionais. Gestão escolar.

\begin{abstract}
This work discusses the training of school principals as a preponderant factor to achieve improvement in public educational quality. With a priority cut in the education state network of Minas Gerais, the available public policies (regarding the theme) are presented and briefly analyzed. From Lück (2000 and 2009), Paro (2010), Teixeira and Malini (2012), among others, the theoretical basis is built that aims to answer the question: Why form directors? From the formative hiatus found, the importance of the work is built around the announcement of the lack of more systematized public policies in the state education network. It can be deduced that this type of research by the academy can be preponderant in the process of indicating the theme for insertion in the agenda of public-educational policies.
\end{abstract}

KEYWORDS: Training of directors. Educational public policies. School management.

\section{RESUMEN}

El trabajo discute la formación de directores de escuelas de educación básica como factor preponderante para que se alcance mejoría en la calidad educativa pública. Con un recorte prioritario en la red de estado de educación de Minas Gerais, las políticas públicas (relativas al tema) disponibles son presentadas y brevemente analizadas. A partir de Lück (2000 y 2009), Paro (2010), Teixeira y Malini (2012), entre otros, se construye la base teórica que pretende responder a la pregunta: ¿Por qué formar directores? A partir de los hiatos formativos constatados, la importancia del trabajo se construye en torno al anuncio de la carencia de políticas públicas más sistematizadas en la red estadual de educación investigada. Se desprende que este tipo de investigación por la universidad puede ser preponderante en el proceso de indicación del tema para inserción en la agenda de las políticas público-educativas.

PALABRAS-CLAVE: Formación de directores. Políticas públicas educativas. Gestión escolar. 


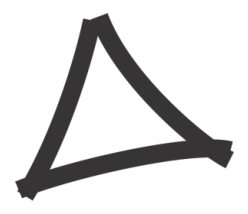

\section{FORMAÇÃO DE DIRETORES - INTRODUÇÃO COM JUSTIFICATIVA}

A partir dos discursos governamentais e das referências midiáticas é possível depreender certa centralidade nos problemas referentes ao oferecimento de uma educação pública de qualidade. Contudo, para além das expressões e destaques da mídia é preciso que políticas públicas em educação sejam pensadas e, principalmente, implementadas visando o alcance de substancial melhoria educacional.

Sabe-se que há bastante complexidade quando tratamos de qualidade educacional e fatores diversos podem interferir nos resultados acadêmicos e sociais obtidos pelas escolas públicas. Destarte, torna-se cara uma dessas variáveis de influência sobre a melhoria da educação oferecida: a formação do profissional que está à frente da instituição escolar. Nesse contexto, o trabalho em tela pretende discutir as possibilidades e limites existentes para a formação do diretor ${ }^{1}$ de escola pública de educação básica.

A justificativa para o desenvolvimento deste trabalho se constrói na trajetória profissional do pesquisador, enquanto gestor de escola estadual mineira, e no fato da especificidade do trabalho do diretor demandar atenção especial para a qual ainda não se dispõe de literatura que elucide as questões relacionadas ao seu estudo objetivo (LÜCK, 2000). Nesse sentido, Paro (2010, p. 766) afirma que é intrigante "a relativa escassez, no âmbito das investigações sobre a realidade escolar no Brasil, de estudos e pesquisas a respeito da natureza e do significado das funções do diretor de escola à luz da natureza educativa dessa instituição". Portanto, torna-se necessário apontar para a carência de pesquisas (stricto sensu) que foquem na formação do diretor escolar. Segundo Fernandes (2015) entre 2011 e 2012 o repositório da CAPES contou com 15 pesquisas inscritas no tema da formação de diretores, enquanto há mais de 6.600 sobre formação docente. Além disso, considera-se que as pesquisas acadêmicas inscritas na temática podem ter como uma das principais contribuições a indicação da necessidade de formulação/reformulação de políticas públicas na área, haja vista a existência de poucos dispositivos que possam pressionar o poder público para a inserção desse tema na agenda das políticas.

\footnotetext{
${ }^{1}$ Optou-se pelo uso dos termos "diretor" e "gestor" como sinônimos, mesmo entendendo que alguns autores fazem distinção semântica na aplicação dessas palavras.
} 


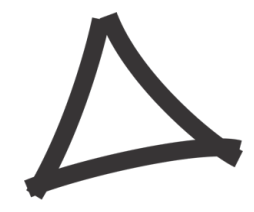

Por se tratar de um texto que parte das ideias e apontamentos de pesquisa de mestrado recém realizada ${ }^{2}$, o recorte escolhido foram as políticas públicas existentes para a formação do diretor de escola estadual de Minas Gerais.

Objetivando demonstrar a relevância do tema, nas próximas seções apresentar-se-ão os pressupostos teóricos e a metodologia utilizada na pesquisa para, a partir destes, analisar os dados e indicar os principais resultados.

\section{POR QUE FORMAR DIRETORES? - PRESSUPOSTOS TEÓRICOS.}

Ao tratar-se da qualidade educacional é preciso ter a perspectiva de que a formação de diretores de escolas básicas pode contribuir substancialmente para o seu alcance. Seria ingenuidade afirmar que a formação de diretores é o fator mais importante para a melhoria educacional, mas torna-se leviandade desconsiderar esse fator entre aqueles que têm caráter fundamental.

Em um relatório de pesquisa etnográfica com quatro diretores escolares no Rio de Janeiro e Recife, Burgos (2016) chega à seguinte conclusão:

O que a pesquisa etnográfica permitiu compreender, afinal, é que se sobra vontade e
dedicação aos diretores escolares, faltam competências técnicas mais específicas
para a gestão de um ambiente tão complexo como são as escolas [...]. Para reverter
esse quadro, além de um forte investimento na capacitação técnica do diretor, será
preciso construir politicamente um novo consenso a respeito do papel da escola [...].
Para essa escola existir, o diretor terá que ter as bases da sua autoridade
reconstruídas, aliando competência administrativa e condições institucionais
compatíveis com o exercício de uma verdadeira liderança política e pedagógica da
escola (pp. 06 e 07).

A partir da citação é possível depreender que o autor condiciona à competência do diretor a reconfiguração do papel da escola na sociedade. Desse profissional é exigida competência técnica e política, uma vez que sua mediação configura a sinergia dos atores escolares em torno de um projeto pedagógico. Este último só pode ser efetiva e eficazmente implementado a partir de forte caráter técnico gestor. É através do planejamento e organização do trabalho escolar, do monitoramento de processos educacionais, da avaliação

\footnotetext{
${ }^{2}$ Trata-se da pesquisa de mestrado do autor, inscrita no Programa de Pós-graduação em Gestão e Avaliação da Educação Pública da UFJF, que teve como objetivo geral analisar as dificuldades da gestão escolar estadual em sua dimensão administrativa.
} 


\section{$\Delta$}

institucional, da gestão de resultados, entre outros (LÜCK, 2009) - presentes num cabedal técnico - que o gestor conseguirá atingi-lo.

Além disso, segundo Teixeira e Malini (2012) os processos de descentralização educacional tornaram a escola locus de interpretação das políticas públicas, ao invés de apenas implementá-las. Cabe, portanto, ao diretor de escola liderar a sua equipe na tarefa da interpretação e implantação das diretrizes político-públicas. Instaura-se aqui pressupostos claros da necessidade da formação gestora na contemporaneidade para a consecução de competência técnico-gerencial e política, que motive a equipe escolar em torno desse projeto de educação (viés político) e que também monitore as ações para que estas culminem em resultados efetivos (viés gerencial/técnico).

Desta forma, concebe-se que as competências profissionais exigidas para o exercício do cargo de gestor escolar são imprescindíveis para que essa gestão se efetive de maneira eficaz. Para Lück (2009), as competências profissionais podem ser vistas através de duas perspectivas distintas, todavia interligadas: a da função/profissão em si ou a do sujeito que a exerce. No primeiro caso competência é o conjunto de padrões mínimos requeridos para o bom desempenho das responsabilidades relativas ao tipo de atividade profissional. No segundo, resulta da capacidade em se executar uma ação específica com alcance dos objetivos pretendidos. Assim, competência é o pressuposto que visa evitar que qualquer atividade seja executada a partir do ensaio e erro (LÜCK, 2009).

Diante da importância que as competências profissionais tomam no contexto da gestão de escola, é preciso avaliar o quanto as políticas públicas educacionais têm se voltado para o seu desenvolvimento. Em detrimento de apontar responsáveis pela não construção destas competências - sejam os órgãos gestores de educação ou o próprio diretor escolar por não as ter desenvolvido - é preciso trazer à tona a discussão e apontar a necessidade da inserção da temática na agenda das políticas. Nesse sentido, pode-se considerar a pesquisa acadêmica como um possível "gatilho" para a proposição de uma agenda, já que parece não haver grande alarde midiático ou políticos indicando a necessidade desta inserção - cita-se a mídia e os políticos por serem estes meios os mais contundentes para a construção das agendas político-públicas. 


\section{$\Delta$}

Por outro lado, é preciso observar que uma das dificuldades da formação dos diretores de escola se constrói pela complexidade das atividades a serem exercidas, por haver diversas dimensões implicadas na gestão, o que exige múltiplos conhecimentos, habilidades e atitudes (LÜCK, 2009).

Supondo que o diretor de escola, enquanto professor, consiga desenvolver minimamente a gestão do pedagógico escolar, sem formação inicial e continuada para o desenvolvimento das demais dimensões, a falta de tempestividade e eficácia trará prejuízo à escola como um todo, já que as demais dimensões são substrato para que os objetivos escolares - pedagógicos - sejam atingidos.

Teixeira e Malini (2012) e Machado (2000) associam a formação de diretores à eficácia da escola. Esta última autora liga o padrão de gestão desenvolvido pela escola ao tipo de liderança construída, afirmando que fazem diferença fundamental nos resultados de aprendizagem. Deste modo, é válido ressaltar que o tipo de formação do gestor influenciará nas competências (in)existentes à frente da escola, que em última instância incide sobre os resultados discentes e a qualidade destes. Machado (2000, p. 100), neste contexto, indaga se as escolas e suas lideranças estão preparadas para lidar com as novas exigências da gestão escolar, considerando os processos de responsabilização, a avaliação de resultados, gestão das equipes escolares entre outras ações inerentes às atribuições diretivas. A autora finaliza: "estas e outras questões reforçam a ideia de capacitação das lideranças escolares como um dos meios a serem utilizados na consolidação do projeto de autonomia escolar".

Apesar da importância da formação de diretores ratificada no trecho imediatamente anterior e em todo texto desta seção, é preciso indicar que, por serem múltiplas as tarefas do gestor de escola, torna-se um desafio para qualquer rede executar formações recorrentes e que tratem dos diversos aspectos da gestão.

\section{MATERIAIS E MÉTODOS}

A pesquisa foi pautada prioritariamente no método qualitativo, especialmente quando se tratou da análise dos dados. Com enfoque na rede de estado de educação de Minas Gerais foi adotada uma amostra por conveniência (proximidade da regional de ensino em relação à 


\section{$\Delta$}

residência do pesquisador). Deste modo a pesquisa de campo aplicou, censitariamente, questionários estruturados aos 210 diretores da Superintendência Regional de Ensino (SRE) Metropolitana $\mathrm{B}^{3}$ e obteve uma margem de $69,5 \%$ de respondentes. Além disso, foram entrevistados 14 diretores escolares e a Diretora da Diretoria Administrativa e Financeira (DAFI) da referida regional. Para uma melhor contextualização temática foi feita, ainda, pesquisa documental indicando, por um lado, as políticas públicas de formação de diretores disponíveis no campo pesquisado e, por outro, as atividades necessariamente atribuídas aos gestores escolares mineiros. A partir dos dados coletados por meio de distintos instrumentos de pesquisa foi possível albergar de forma mais abrangente o objeto de estudo.

\section{ANÁLISE DOS DADOS E RESULTADOS}

Apesar do número substancial de dados coletados na pesquisa ora apresentada, tanto a partir das entrevistas quanto da aplicação dos questionários estruturados, para esta seção priorizaram-se os dados encontrados durante a pesquisa documental. Esta opção de percurso foi selecionada para demonstrar as atribuições do diretor escolar contemporâneo cotejando os programas de formação disponíveis ou a falta destes, o que figurou como o principal resultado da pesquisa.

\subsection{As atribuições do diretor escolar contemporâneo}

As atividades relacionadas à gestão escolar foram profundamente alteradas pelas reformas educacionais recentes: a popularização da educação, os processos de descentralização educacional e a celeridade alcançada através das novas tecnologias. Fortunatti (2008) concebe que as tarefas dos diretores das escolas públicas no terceiro milênio são muito mais complexas do que as exercidas nas mesmas escolas anos atrás: "é necessário reconhecer que novos diretores estão submetidos a um rol mais complexo de responsabilidades" (FORTUNATTI, 2008, p. 52).

${ }^{3}$ A Secretaria de Estado de Educação de Minas Gerais (SEE/MG) é dividida em 47 (quarenta e sete) SRE's alocadas em diversas regiões do Estado, organizadas em polos regionais (MINAS GERAIS, 2016). A SRE Metropolitana B é a maior das superintendências do estado, possuindo 210 escolas a ela jurisdicionadas (MINAS GERAIS, 2017). 


\section{$\Delta$}

O fazer gestor se constitui num equilíbrio de competências pedagógicas, administrativas e financeiras. São diversas atribuições referentes a demandas da comunidade escolar, dos órgãos superiores das redes educacionais, como também advindas das mudanças estruturais da educação pública. A partir da descentralização educacional, por exemplo, houve maior autonomia na execução dos projetos pedagógicos escolares, por outro lado, também, maior rigor gerencial nas execuções e prestações de contas. Assim, para uma gestão que responda eficazmente às exigências das Secretarias de Educação, mas que também tenha comprometimento com a realidade na qual a escola está imersa, ou seja, que responda aos anseios da comunidade atendida pela escola, ao gestor é requerida uma gama de conhecimentos nas diversas áreas do saber com "mediação administrativa sui generis, tanto em termos de racionalização do trabalho quanto de coordenação do esforço humano coletivo" (PARO, 2010, p. 776).

Em se tratando da rede de estado de educação de Minas Gerais, na estrutura organizacional das escolas é previsto que o gestor seja um professor (licenciado em quaisquer das disciplinas) ou especialista da educação básica (pedagogo), aprovado em certificação para diretores, indicado pela comunidade escolar e nomeado pelo governador do estado (MINAS GERAIS, 2015a; MINAS GERAIS 2015b). Desta forma, o professor passa a executar funções administrativas, financeiras e de gestão de pessoal, além de precisar gerir a contento o pedagógico escolar. Apesar da complexidade que há na transição entre as atribuições docentes e a nova função gestora, nota-se não haver preparo ou formação inicial que garanta ao novo diretor as ferramentas necessárias à execução das suas atividades. Isso pode caracterizar um problema já que a formação de professores, em tese, não o dota das competências técnicas necessárias ao fazer gestor em todas as suas dimensões.

No quadro 1 são apresentadas algumas das atribuições do gestor visando dar substância à competência técnica exigida.

Quadro 1: Atribuições do diretor escolar estadual de Minas Gerais

\begin{tabular}{|c|c|}
\hline \multicolumn{1}{|c|}{ Responsabilidade/competência exigida } & \multicolumn{1}{c|}{$\begin{array}{c}\text { Dimensão } \\
\text { implicada }\end{array}$} \\
\hline $1 . \quad \begin{array}{l}\text { Responder integralmente pela escola, exercendo em regime de } \\
\text { dedicação exclusiva as funções de direção; }\end{array}$ & Administrativa \\
\hline $2 . \quad \begin{array}{l}\text { Cumprir e fazer cumprir as determinações da Secretaria de Estado } \\
\text { de Educação de Minas Gerais (SEE/MG); }\end{array}$ & Administrativa \\
\hline
\end{tabular}




\section{$\Delta$}

Revista Triângulo

www.seer.uftm.edu.br/revistaeletronica

\begin{tabular}{|c|c|}
\hline 3. Garantir o cumprimento do calendário escolar; & Administrativa \\
\hline $\begin{array}{l}\text { 4. Zelar para que a escola estadual sob sua responsabilidade ofereça } \\
\text { serviços educacionais de qualidade; }\end{array}$ & $\begin{array}{l}\text { Administrativa/ } \\
\text { Pedagógica }\end{array}$ \\
\hline 5. Coordenar o Projeto Pedagógico; & $\begin{array}{l}\text { Administrativa/ } \\
\text { Pedagógica }\end{array}$ \\
\hline $\begin{array}{l}\text { 6. Apoiar o desenvolvimento da avaliação pedagógica e divulgar seus } \\
\text { resultados; }\end{array}$ & $\begin{array}{l}\text { Administrativa/ } \\
\text { Pedagógica }\end{array}$ \\
\hline 7. Adotar medidas para elevar os níveis de proficiência dos alunos; & Pedagógica \\
\hline $\begin{array}{l}\text { 8. Estimular o desenvolvimento profissional dos professores e demais } \\
\text { servidores em sua formação e qualificação; }\end{array}$ & Administrativa \\
\hline $\begin{array}{l}\text { 9. Organizar o quadro de pessoal e controlar a frequência dos } \\
\text { servidores; }\end{array}$ & Administrativa \\
\hline 10. Conduzir a Avaliação de Desempenho da equipe da escola; & Administrativa \\
\hline $\begin{array}{l}\text { 11. Garantir a legalidade e a regularidade do funcionamento da escola } \\
\text { e a autenticidade da vida escolar dos alunos. }\end{array}$ & Administrativa \\
\hline $\begin{array}{l}\text { 12. Zelar pela manutenção dos bens patrimoniais, do prédio e } \\
\text { mobiliário escolar; }\end{array}$ & Administrativa \\
\hline 13. Assegurar a regularidade do funcionamento da Caixa Escolar; & $\begin{array}{l}\text { Administrativa/ } \\
\text { Financeira }\end{array}$ \\
\hline 14. Observar e cumprir a legislação vigente. & Administrativa \\
\hline
\end{tabular}

Fonte: Adaptado a partir de ARAÚJO, 2017.

O quadro 1 apresenta as atribuições do diretor nas diversas dimensões gestoras. Tais atribuições são bastante distintas da função docente propriamente dita, sobretudo se se levar em conta as demandas financeiras e administrativas, para as quais, não raro, o novo diretor não detém a técnica necessária, seja por nunca ter executado tais funções ou por sua formação inicial não tratar de tais aspectos.

A partir das mudanças apresentadas do perfil profissional do professor para o de diretor escolar e das exigências inerentes à essa função, deduz-se que o processo de investidura no cargo de diretor escolar na rede analisada apresenta lacunas, presumindo que $\mathrm{o}$ professor ao assumir tal cargo não tem em sua formação, no geral, o preparo para lidar com todas as novas atribuições. 


\title{
$\Delta$
}

\subsection{Políticas Públicas de formação de diretores na rede estadual de educação mineira}

Já na década de 1960, Anísio Teixeira criticava a excepcionalidade do Brasil quanto à falta de formação dos administradores escolares (que podem ser considerados os atuais diretores), alegando que não havia administração no sentido real, muito menos na área educacional, uma vez que qualquer pessoa poderia dirigir as escola ou administrar o ensino: "É evidente que o país acha que para isso não é preciso preparo" (TEIXEIRA, 1961, p. 01).

Por outro lado, baseado na situação da época - relacionado ao processo de popularização da educação - Teixeira indicava a necessidade de mudança desse quadro:

\begin{abstract}
Como tenho de educar tôda a população, terei de escolher os professores em tôdas as camadas sociais e intelectuais e, a despeito de todo o esfôrço de prepará-los, trazê-los para a escola ainda sem o preparo necessário para que dispensem eles administração. Esta se terá de fazer altamente desenvolvida, a fim de ajudá-los a realizar aquilo que faziam se fôssem excepcionalmente competentes. [...] Por que somos hoje tão necessários, e antigamente não o éramos? Por que antes não se cogitava de preparar o Administrador Escolar, e hoje precisamos fazê-lo? Porque o problema se fêz agora extremamente complexo [...] (TEIXEIRA, 1961, p. 03).
\end{abstract}

Teixeira (1961) traz a assertiva de que os professores deixam de ser melhor selecionados, pela demanda aumentada, e que por isso o diretor escolar - o administrador tem de ser extremamente competente, considerando o contexto à época.

Mesmo após mais de meio século, esse problema de formação parece se repetir, pelo menos no caso de Minas Gerais, quando não se mantém sistematicamente na rede estadual de educação políticas públicas de formação de gestores, especialmente quando se trata de formação inicial para o desempenho do cargo.

Trazendo um recorte dos últimos 5 anos, estiveram vigentes na rede em tela os seguintes programas de formação inicial/continuada: o Progestão, o Escola de Gestores, o Programa de Certificação de Diretores e o Mestrado Profissional em Gestão e Avaliação da Educação Pública (PPGP).

O Progestão - Programa de Capacitação a Distância para Gestores Escolares criado pelo CONSED - foi oferecido na modalidade de educação a distância (EAD) e teve como objetivo capacitar líderes escolares para o desenvolvimento da gestão democrática como pré- 


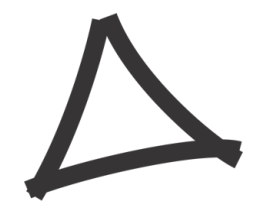

requisito do sucesso escolar do aluno (CONSED, 2016). O programa se configurou através de parcerias com Secretarias Estaduais e Municipais de Educação e atingiu diversos estados brasileiros, inclusive em Minas Gerais, onde esteve presente entre os anos de 2004 e 2014.

O Programa Nacional Escola de Gestores da Educação Básica fundou uma série de ações formativas para diretores de escola em todo o país a partir de 2005. Gomes, Santos e Melo (2009, p. 264) apontam que o MEC coordenou iniciativas como cursos de extensão e atualização em Gestão Escolar, além do Curso de Pós-Graduação lato sensu em Gestão Escolar, com 400h de duração, implementado pela SEB/MEC a partir de 2006/2007 em parceria com IFES, secretarias estaduais e municipais de educação. Pela maior relevância do curso de pós-graduação lato sensu, o Programa Escola de Gestores se confunde, não raro, com este último. A justificativa para a formulação do Programa se encontra na necessidade de formar gestores escolares com posturas profissionais em consonância com o caráter público da educação e com a busca de sua qualidade social, "baseada nos princípios da gestão democrática, olhando a escola na perspectiva da inclusão social e da emancipação humana" (MEC, 2007, p. 04).

Em Minas Gerais a participação dos diretores estaduais no Escola de Gestores foi bastante inferior se comparada ao número de dirigentes municipais participantes, deixando transparecer que na rede estadual o programa não teve grande divulgação e incentivo - o que talvez possa ser explicado pelas diferenças dos governos estadual e federal, nas questões de cunho político-partidário. O programa teve a sua última edição na UFMG em 2014 e na UFOP em 2015.

A rede estadual de educação mineira, além de utilizar-se dos programas acima mencionados, de abrangência nacional, tem o programa de certificação ocupacional de diretores da rede estadual de educação de Minas Gerais (PCD). Este se configura como o único programa para diretores projetado e implementado pela própria rede. O PCD é constituído exclusivamente de uma prova objetiva, que afere capacidades básicas para possível ingresso do professor ou especialista da educação (pedagogo) no cargo de diretor. O candidato que obtiver $60 \%$ de acertos na prova se torna certificado e apto para participar do processo de indicação para diretores escolares pelas suas respectivas comunidades. Pode-se questionar o caráter formativo de tal processo - alegando que uma prova é estritamente 


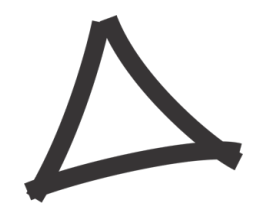

seletiva -, entretanto, para a SEE/MG, ao estabelecer a certificação como única política pública que alberga todos os diretores escolares estaduais, sem disponibilizar outra formação inicial que possa prepará-los para o cargo, denota julgar que o processo seja capaz de "munir" os partícipes das competências técnicas necessárias para a atuação enquanto diretores: "a Certificação Ocupacional busca, por meio de prova, avaliar conhecimento pedagógico, técnico e as competências necessárias ao satisfatório desempenho do cargo de Diretor de Escola Estadual” (MINAS GERAIS, 2015b, p. 37).

A crítica ao PCD recai exatamente no fato deste se constituir apenas de uma prova objetiva e não trazer algum preparo que anteceda tal avaliação ou um curso subsequente.

Uma importante iniciativa de formação de diretores que vem sendo realizada pela SEE/MG é a contratação de vagas no Programa de Mestrado Profissional em Gestão e Avaliação da Educação Pública (PPGP), coordenado pelo Centro de Políticas Públicas e Avaliação da Educação (CAEd), da Universidade Federal de Juiz de Fora (UFJF). A referida secretaria contratou nos anos de 2015, 2016 e 2017 um total de 120 vagas para que os diretores escolares estaduais da carreira efetiva pudessem concorrer a estas e realizar o curso stricto sensu com todas as despesas pagas pela SEE/MG. Apesar de extremamente válida, a política pública abarca pouco mais de $2 \%$ dos diretores escolares estaduais, o que não lhe dá um resultado mais vasto, embora os efeitos possam ser medidos a partir de outras reverberações.

Apesar da importância dos programas nesta seção apresentados, salienta-se que apenas o PCD encontra-se em vigor atualmente na rede pesquisada. Deste modo, depreendese que o processo de formação de diretores em Minas Gerais carece de maior sistematização, com cursos de formação inicial e continuada, haja vista a mudança das atribuições do professor que passa a ser diretor escolar. Além disso, considera-se que políticas púbicas de formação de gestores podem ter influência substancial sobre a qualidade da educação pública ofertada. 


\section{$\Delta$}

\section{CONSIDERAÇÕES FINAIS}

$\mathrm{Na}$ pesquisa fonte das principais ideias deste trabalho ${ }^{4}$, ficou evidenciado, portanto, que a rede estadual de educação de Minas Gerais teve como principais formações disponibilizadas aos diretores escolares o Progestão e o Escola de Gestores (não tendo classificado entre estas o PPGP pela sua pouca abrangência entre os diretores, conforme anteriormente mencionado). Estes programas destacaram dois vieses: o direito à educação e o projeto político pedagógico como condições da melhoria da gestão escolar - o Escola de Gestores; e a gestão democrática e o papel da participação dos diversos segmentos nas ações gestoras - o Progestão. Vê-se que mesmo estes programas não albergavam todas as dimensões da gestão escolar, sem contar que não estão em vigência atualmente. Resta aos diretores de escola o programa de certificação de diretores, que, como já indicado, tem grandes limitações por se tratar exclusivamente de uma prova.

Assim, os dados coletados em campo, ratificaram a suposição de que havia hiatos na formação dos diretores escolares da rede estadual de educação de Minas Gerais, e que as políticas de formação disponibilizadas não deram/dão conta da formação de gestores em todas as dimensões da gestão escolar.

É notória, ainda, a premente necessidade de formação de diretores a partir de alguns documentos oficiais relacionados às políticas públicas em educação. Pode-se referir neste contexto, por exemplo, ao relatório sobre o cumprimento das metas do Plano Nacional de Educação (PNE) 2001-2008 e no PNE vigente (Lei 13.005/2014). No primeiro deles é indicado que iniciativas que pretendam contribuir para a melhoria da qualidade educacional devem levar em consideração os eixos centrais do financiamento e da gestão (BRASIL, 2009). No PNE atual uma das estratégias para a meta 19 é o desenvolvimento de programas de formação de diretores escolares (BRASIL, 2014). Estas referências sublinham a carência do país em geral de construção de políticas educacionais de formação de diretores. Espera-se que com trabalhos como este o tema possa ser evidenciado e alcance destaque para a agenda das políticas públicas.

\footnotetext{
${ }^{4}$ Vide nota de rodapé 2 deste trabalho.
} 


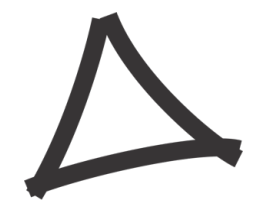

Revista Triângulo

www.seer.uftm.edu.br/revistaeletronica

\section{REFERÊNCIAS}

ARAÚJO, Eduardo Santos. Gestão Escolar na Rede Estadual de Minas Gerais: Desafios da Formação Administrativa do Diretor. Dissertação (mestrado profissional) - Universidade Federal de Juiz de Fora, Faculdade de Educação/CAEd. Programa de Pós Graduação em Gestão e Avaliação da Educação Pública. 2017. Disponível em:

$<$ http://www.mestrado.caedufjf.net/wp-content/uploads/2017/10/EDUARDO-SANTOSARAUJO REVISADO.pdf>. Acesso em: 19 fev. 2018.

BRASIL. Avaliação do Plano Nacional de Educação 2001 - 2008. Volume 3. Magistério da Educação Básica Financiamento e Gestão Educacional. Brasília: Inep, 2009. Disponível em: <http://fne.mec.gov.br/images/pdf/volume3.pdf>. Acesso em: Ago. 2017.

. Lei n ${ }^{\circ} 13.005$, de 25 de junho de 2014. Aprova o Plano Nacional de Educação - PNE e dá outras providências. Diário Oficial da União, Brasília, DF, 26 jun. 2014.

BURGOS, Marcelo Tadeu Baumann. O Cotidiano das Diretoras. Artigo. Disponível em: $<$ http://www.ppgp2014.caedufjf.net/pluginfile.php/3594/mod_resource/content/1/LEGE_Ocotidiano-das-diretoras.pdf>. Acesso em: 13 abr. 2016.

Conselho Nacional de Secretários de Educação (CONSED). O que é o PROGESTÃo. Disponível em: <http://www.consed.org.br/gestao-da-educacao/progestao/o-que-e-oprogestao >. Acesso em: 27 set. 2016.

FERNANDES, Cássia do Carmo Pires. O programa escola de gestores da educação básica e seus efeitos para a formação de gestores escolares em Minas Gerais. Tese (Doutorado em educação). Juiz de Fora: UFJF, 2015. Disponível em:

$<$ https://repositorio.ufjf.br/jspui/bitstream/ufjf/184/1/cassiadocarmopiresfernandes.pdf>. Acesso em: 27 ago. 2017.

FORTUNATTI, José. Gestão da educação pública: caminhos e desafios. Porto Alegre: Artmed, 2008. pp. 51-54. Disponível em:

$<$ https://books.google.com.br/books?id=REAfFRXP860C\&pg=PA51\&hl=pt-

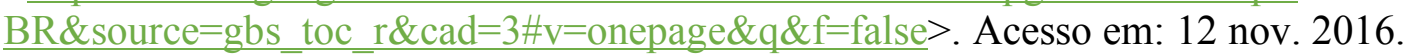

GOMES, Alfredo Macedo; SANTOS, Ana Lúcia Felix dos; MELO, Darci Barbosa Lira. Escola de gestores: política de formação em gestão escolar. RBPAE - v.25, n.2, p. 263-281, mai./ago. 2009. Disponível em:

$<$ http://www.seer.ufrgs.br/rbpae/article/viewFile/19496/11321>. Acesso em: 29 set. 2016.

LÜCK, Heloísa. Dimensões de gestão escolar e suas competências. Curitiba: Editora Positivo, 2009. Disponível em:

$<$ http://www. fundacoes.org.br/uploads/estudos/gestao escolar/dimensoes livro.pdf $>$. Acesso em: 01 ago. 2016. 


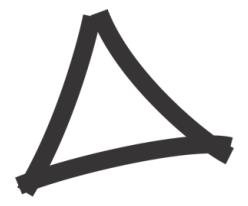

. Perspectivas da Gestão Escolar e Implicações quanto à Formação de seus Gestores. Em Aberto, Brasília, v. 17, n. 72, p. 11-33, fev./jun. 2000. Disponível em: $<$ http://rbep.inep.gov.br/index.php/emaberto/article/download/2116/2085>. Acesso em: 01 ago. 2016.

MACHADO, Maria Aglaê de Medeiros. Desafios a Serem Enfrentados na Capacitação de Gestores Escolares. Em Aberto, Brasília, v. 17, n. 72, fev./jun. 2000, p. 97-112. Disponível em: <http://emaberto.inep.gov.br/index.php/emaberto/article/view/2122/2091>. Acesso em: 02 mar. 2017.

\section{MEC. SECRETARIA DE EDUCAÇÃO BÁSICA. Projeto do Curso de Especialização em} Gestão Escolar (Lato Sensu). Brasília, 2007. Disponível em:

$<$ http://portal.mec.gov.br/index.php?option=com docman\&view=download\&alias=877projeto-pdf\&Itemid=30192>. Acesso em: 29 set. 2016.

MINAS GERAIS. Edital SEE No 03/2015. Certificação Ocupacional de Diretor de Escola Estadual. Divulga normas relativas ao Processo de Certificação Ocupacional de Diretor de Escola Estadual. Imprensa Oficial de Minas Gerais, Minas Gerais, MG, 29 set. 2015a. p. 37-38.

Lista de Escolas (Lista atualizada de escolas estaduais de Minas Gerais. Contém nomes, endereços, telefones e outros dados das instituições). 05 de Maio de 2017. Disponível em: <https://www.educacao.mg.gov.br/parceiro/lista-de-escolas >. Acesso em: 13 mai. 2017.

Disponível em:

\section{Organograma da Secretaria de Estado de Educação de Minas Gerais.}

$<$ https://www.educacao.mg.gov.br/images/stories/organograma/organograma-atualoriginal.jpg >. Acesso em: 08 out. 2016.

. Resolução SEE n ${ }^{\circ} 2795$, de 28 de setembro de 2015. Estabelece normas para escolha de servidor ao cargo de diretor e à função de vice-diretor de escola estadual de Minas Gerais e trata de outros dispositivos correlatos. Imprensa Oficial de Minas Gerais, Minas Gerais, MG, 29 set. 2015b. p. 38-39.

PARO, Vitor Henrique. A educação, a política e a administração: reflexões sobre a prática do diretor de escola. Educação e Pesquisa, São Paulo, v. 36, n.3, p. 763-778, set./dez. 2010. Disponível em: <http://www.scielo.br/pdf/ep/v36n3/v36n3a08>. Acesso em: 01 ago. 2016.

TEIXEIRA, Anísio. Que é administração escolar? Revista Brasileira de Estudos Pedagógicos. Rio de Janeiro, v.36, n.84, 1961. p.84-89. Disponível em:

$<$ http://www.geocities.ws/angesou/anisio.pdf>. Acesso em: 01 ago. 2016.

TEIXEIRA, Beatriz de Basto; MALINI, Eduardo. Formação de diretores: Exigência à melhoria da gestão escolar. III Congresso Ibero Americano de Política e Administração da Educação. 2012. Disponível em: 


\section{Revista Triângulo}

$<$ http://www.anpae.org.br/iberoamericano2012/Trabalhos/BeatrizdeBastoTeixeira res int G T3.pdf>. Acesso em: 29 set. 2016. 